\title{
The Study on the Mode of Students' Professional Qualities Education-Based on Second Classroom Transcripts System
}

\author{
Peng Qing, Ye Yu \\ Ningbo City College of Vocational Technology 315000
}

\begin{abstract}
Keywords: Second Classroom Transcripts; Higher Vocational Colleges; Professional Qualities
\end{abstract}
\begin{abstract}
The Second Classroom Transcripts System, established and improved by the Communist Youth League of Higher Vocational Colleges, adapts to the new trend of economy and conforms to the trend of national education reform, meets the needs of students and serves the students' growth, encourages students to improve their comprehensive quality and helps them to improve their competitiveness. On the basis of the education of the existing students' professional quality, the Virtual Corporation System Platform combining with Second Classroom Transcripts System, Ningbo City College of Vocational Technology can reform the mode of students' professional accomplishment education to make this work more feasible, operational and effective.
\end{abstract}

\section{The Connotation and Value of the Second Classroom Transcripts}

The key points of 2016, worked out by the School and College Department of the Central Committee of the Communist Youth League, points out: CYL should focus on promoting the innovation of the organization and the work system, and the Second Classroom Transcripts System should be set up in the universities and colleges. The Second Classroom Transcripts are divided into 7 modules: ideological growth, practice, public welfare, innovation and entrepreneurship, recreational and sports activities, work resume and technical ability, which have 6 functions: objective record, scientific evaluation, promoting growth, working promotion, public serving and social inclusion, providing scientific reference for school educating and enterprise recruitment.

Through the exploration of curriculum design, system development, system construction, and theory research, the Second Classroom Transcripts forms effective work concept, working mechanism and working method, to clear and definite the scientific connotation, work content and operation logic. The Second Classroom Transcripts will be the important basis for the evaluation of school personnel training, the evaluation of students' comprehensive quality and the recruitment of social employers, by objective record, effective authentication and scientific evaluation. It is of great significant to adapt to the new normal economic situation and conform to the trend of national education reform, it also fits students' needs and serves the growth of students, motivates students to improve their comprehensive quality and helps students improve their employ-abilities and competitiveness.

\section{The Status Qua of Students' Professional Qualities Education in Ningbo City College of Vocational Technology}

The target of Students' Professional Qualities Education in Ningbo City College of Vocational Technology(NCC) has been set to be a "Perfect Staff". Based on the Virtual Corporation System Platform, NCC has been exploring a set of education system for students' professional qualities with the distinctive features of school-enterprise cooperation and the work-integrated learning, taking responsibility education as the core, which plays an important role in students' efficient management and assessment, and achieves good results through constantly adjusting and improving. The Certificate of College Students' Professional Quality Education, provided by NCC, has already been received the attention of the employing units and medias.

However, this system also meets some problems and challenges in its actual operation process. 
(1) Some structural problems of this system

It is indisputable for enterprise management to take "profit" as its goal. However, based on the Virtual Corporation System Platform, evaluating students by "the Branch assets", which can arouse the enthusiasm of the students, and it will inevitably cause the expansion and spread of the students' utilitarian thinking. For example, taking part in the public services, students will be given the corresponding class hours and credits in NCC. Students are no longer enthusiastic about participating in activities after achieving designated hours. Aiming at the sole purpose of obtaining benefits, this action not only deviates from the original intention of public welfare activities and Credit Incentive, but also seriously affects the shaping of students' correct values.

Enterprise management follows the Law of the Jungle and the Survival of the Fittest, which is a radical state of white hot competition; and the fairness of education is more focused, although education management also emphasizes hard work. In general, schools will not give up one student voluntarily because of the lack of personal abilities. So the management of the Virtual Corporation System Platform is more favorable to the outgoing personality of the students who are keen on Student Affairs.

Because of "profitability", the enterprises must emphasize the "achievement", require a clear and detailed management, a single and clear direction of the instruction. Education focuses on the diversification of students' grow up, the same work is more involved, information is more sourced, and directives have multiple goals. Taking the thematic activity of "Seven Colors Tour" as an example, lectures are miscellaneous, the Student Affairs Department is busy dealing with these lectures, the students are tired and exhausted from running about on them.

(2) Some institutional problems of this system

Firstly, the recessive characteristics of professional accomplishment vs the explicit operation of the " corporation system platform". The recessive contents, such as campus culture, learning atmosphere, personal quality and so on, operate explicitly by special lecture, school rules and principles, force student to participate by those rigid rules, which is easy to lead to students' incompatibility.

Secondly, the long-term cultivation of professional accomplishment vs the periodical effect of corporation system platform. The training of the students' professional quality is a slow and gradual process, and emphasizes the long-term and implicit influence of a good campus culture on the students. The evaluation method of the corporation system platform needs further coordination.

Thirdly, the division and cooperation between the Teaching Department and the Student Affairs Department in the process of students' professional quality education. The Student Affairs Department itself is a collection of multiple functional departments, it is in charge of the students' professional quality education. whether it can meet the needs of students' personal development, whether it can interact with the "main position" of the first class to form a positive interaction, these details are still questionable.

Based on the Virtual Corporation System Platform, students' professional quality education meets some problems and challenges in its actual operation process, because of the fragmentation of the second classroom activities, the conflicts between the quantitative assessment and the explicit operation in the education. What's more, the basic role of the CYL organization in the training of students' professional quality is not fully reflected. So, Virtual Corporation System Platform combining with the Second Classroom Transcripts, it can make complementary advantages and improve the students' professional quality education model, making this work more feasible, operational and effective.

\section{The Difficulties of Establishing "Second Classroom Transcripts"}

The Second Classroom Transcripts evaluate and record every single student accurately, which means the high requirement for data collection and processing of the second classroom activities in colleges and universities. Whether the management platform and information technology meet the needs of information processing, it is the technical basis and prerequisite for the generation of "second classroom transcripts". Relying on the network platform, some pilot colleges have 
developed personalized modules, such as activities participation, school time certification, assessment record, report card printing and so on, recording the experience and effect of students' participation in activities and providing the detailed and reliable data.

The record of "Second Classroom Transcripts" is the result of students' participation, not involving in the process. So, in the formulation of evaluation criteria, the functional departments adhere to the principle of "giving priority to objective and giving consideration to subjective", not only establishing the quantitative assessment system according to the objective data, but also taking into account the subjective comprehensive evaluation in the process assessment.

Promoting the effective development of the Second Classroom Transcripts, the functional departments need to communicate and coordinate fully and form a joint force. To make the education work of the Communist Youth League more institutionalized, standardized, systematized and scientific, CYL Organizations at various levels in colleges and universities should organize and carry out the second classroom activities, and complete the related system construction. Try to change the current status that multiple functional departments set up second classroom activities separately, lacking of co-ordination and management.

\section{The "Three Steps" Strategy for the Establishment of the Second Classroom Transcripts System}

Relying on the Virtual Corporation System Platform of the students' professional quality education, the second classroom transcripts system will be set up by the "three steps" strategy.

The first step: Clarify the content of the project and Do a good job of guidance. According to the reality and characteristics of the Corporation System Platform, the administrations should further clarify and sum up the types of second class activities, the mature projects can be brought into the assessment system, and the immature modules would be used as nurturing projects. A scientific and dynamic second class curriculum system should be established to do a good job in the thought and content of the second class.

The second step: Research the assessment method and Record the second class achievements. The achievement is the core and key of the second classroom transcripts system, and a systematic and scientific assessment is an important link in the system implementation. Taking full advantage of the first class model and combining the characteristics of the second classroom activities, the administration should set up a certain assessment standard and record by scientific methods, for example, the attendance, the content of activities, and the results of the activities in the second classroom activities could be mapped to the attendance, the usual performance and the final results in the first classroom.

The third step: Building a network platform and Pay attention to the result analysis. The result analysis should be emphasized during the establishment of the second class transcripts system, and the situation of the second class education should be presented explicitly. For students, on the one hand, it can make students gain a sense of harvest, on the other hand, it urges students to selectively participate in the weak links in the second class activities; for colleges, through large data analysis, it provides both scientific data for the supply side reform of the second class education, and effective data for the development of students' personality; for employers, An objective judgment of students' comprehensive quality can be made by the use of the second classroom transcripts, which is good for enterprises to recruit suitable talents.

Relying on the Virtual Corporation System Platform of the students' professional quality education, the "Three Steps" Strategy for the Establishment of the Second Classroom Transcripts System is a process of systemic circulation, the previous step is the basis and guarantee for the latter one. This strategy will provide effective ideological guidance for the Establishment of the Second Classroom Transcripts System, promoting the institutionalization, standardization and scientification of students' professional quality education. 


\section{The Significance of the Establishment of the "Second Classroom Transcripts" for the Students' Professional Quality Education}

The systematization of second classroom activities. During establishing the system of "second classroom transcripts", the overall structure of the second class contents could be combed systematically, a systematic and systematic position of the second class should be formed at the macro level, changing the status quo of the fragmented work in the students' professional quality education.

The curriculum of second classroom activities. On the basis of the practice of the current students' professional quality education, combining professional features and clarifying the type of the second class activities, the administration incorporates mature projects into the talent training program, and the immature modules would be used as nurturing projects. Let the students have a real harvest by establishing a scientific and dynamic second class activity curriculum system.

The functionalization of CYL organization. Carrying out this transcripts system, CYL organization plans the students' professional quality education as a whole and strengthen the educational function of itself in colleges and universities.

Individualization of students' education. Through the second classroom transcript system, each student's participation in every activity has been recorded, their performance in the university will be certificated involving in curriculum vitae, social practice, voluntary service, innovation and excellence, characteristic development etc. as a result, this system will provide a precise "portrait" for every student.

Socialization of work effect. In the environment of the market economy, the society is an important evaluation party for the students' good or not. The second classroom transcripts system, carrying out by CYL Organization in colleges and universities, provides an important reference for the society to evaluate the competitiveness of the students, and builds an effective connection platform among the students, school and society.

\section{References}

[1] Zhao jian: The Exploration of Building " the Second Classroom Transcripts" on the "PU" Platform[J], Journal of Nanjing Industry College of Vocational and Technical, 2016(06).

[2] Qu xueyan: Some Thoughts on Strengthening the Construction of the Second Classroom in Agricultural College[J], Journal of Jiangxi Agricultural University: Social Science Edition, 2006(06).

[3] Li mao: Work hard to Build a New System of Second Class Work in Higher Vocational Colleges-The Practice and Exploration of the Work of "Second Class Transcripts" in Zhongshan Polytechnic[J], Frontier Discovery, 2016(02). 